\title{
Paradigmas del ser humano: aproximación al camino a la complejidad
}

\section{Paradigms of human beings: Way to the complexity}

\section{Paradigmas do ser humano: abordagem ao caminho da complexidade}

\author{
Ludwig Schmidt H.*
}

Fecha de recepción: 15 de septiembre 2017

Fecha de evaluación: 16 de septiembre de 2017

Fecha de aceptación: 5 de octubre de 2017

Fecha de publicacion en linea: 1 de diciembre de 2017

DOI: http://dx.doi.org/10.18359/reds.3245

Cómo citar este artículo:

Schmidt H., L. (2017). Paradigmas del ser humano: aproximación al camino a la complejidad. Revista Educación y Desarrollo Social, 11(2), 108-130. DOI: org/10/18359/reds.3245.

Doctor en Ingeniería Biomédica y Hospitalaria, PhD. en Ciencias de la Salud y postdoctorado en Educación. Profesor titular de la Universidad Católica Andrés Bello (UCAB), la Universidad Central de Venezuela y la Universidad Nacional Abierta y a Distancia. Representante profesoral ante el Consejo Universitario de la UCAB. Miembro de Cortesía en la Sociedad Venezolana de Historia de la Medicina y de la Sociedad Nacional de Medicina. Miembro de la Federación Latinoamericana y del Caribe de Instituciones de Bioética. Asociación Española de Bioética, Sociedad Internacional de Bioética-Sección Latinoamérica, Profesionales por la Ética, Global Bioethical Network y, Unesco-Global Ethics Observatory. Correo electrónico: lschmidt01@gmail.com 
Paradigmas del ser humano: aproximación al camino a la complejidad

\title{
Resumen
}

El ser humano es una especie que se caracteriza por ser única, con individualidad, integralidad e intimidad intransferible, un ser finito y relacional que busca su trascendencia en la felicidad y en la ciencia (bien-ser), en la convivencia y cotidianidad (bien-estar) y a través de la satisfacción de sus necesidades y vocación de servicio (bien-hacer). Un ser como todo ser vivo que se relaciona, participa y convive con otras especies en sociedad, en un mundo complejo y variante, buscando una homeostasis permanente en sus diversos ecosistemas, pero que por su propia actuación genera diversos impactos antropogénicos y sociales, en la temporalidad y cotidianidad en la que habita. Diversos especialistas han intentado definir al hombre y a la mujer, según sus carestías y expectativas, dentro de un marco disciplinar y una hermenéutica. Se han establecido diversos paradigmas a lo largo del tiempo y según diversos criterios, con miras a definir un ser-ético en una sociedad.

Palabras clave: ser humano, especie, ecosistema, sociedad, complejidad, hermenéutica.

\begin{abstract}
The human being specie is characterized by being unique, independent, with integrity and non-transferable intimacy. A finite and related being that seeks it's transcendence in happiness and science (be well), in coexistence and it's everyday (well-being), and through satisfying their needs and vocation of service (well-done). A being like every living thing that gets related, participates and coexists with other species in society- in a complex and variant world-, seeking a permanent homeostasis in different ecosystems; but for their own development, generates various anthropogenic and social impacts, at the temporality and everyday life in which it lives. Several experts have tried to define the man and the woman, according to its own lacking and expectations within a disciplinary framework and hermeneutics. Different paradigms have been established over time and according to various criteria, in order to define an un-ethical being in a society.
\end{abstract}

Keywords: Human, species, ecosystem, society, complexity, hermeneutics.

\section{Resumo}

O ser humano é uma espécie que se caracteriza por ser única, com individualidade, integralidade e intimidade intransferível, um ser finito e relacional que busca a transcendência na felicidade e na ciência (bem-ser), na convivência e no cotidiano (bem-estar) e através da satisfação de suas necessidades e vocação de serviço (bem-fazer). Um ser como todo ser vivo que se relaciona, participa e coexiste com outras espécies da sociedade, num mundo complexo e variante, procurando uma homeostase permanente em seus diversos ecossistemas, mas que por sua própria atuação gera diversos impactos antropogênicos e sociais, na temporalidade e no dia-a-dia em que vive. Vários especialistas tem tentado definir ao homem ou à mulher, de acordo com suas deficiências e expectativas, dentro de um quadro disciplinar e uma hermenêutica. Vários paradigmas foram estabelecidos ao longo do tempo e de acordo com diferentes critérios, com o objetivo de definir um ser-ético numa sociedade.

Palavras-chave: ser humano, espécie, ecossistema, sociedade, complexidade, hermenêutica. 
"A veces sentimos que lo que hacemos es tan solo una gota en el mar, pero el mar sería menos si le faltara una gota. Beata Madre Teresa de Calcuta".

\section{Proemio}

El presente artículo es parte de una línea de investigación iniciada con la Cátedra Institucional de Introducción al Estudio del Hombre en 1994, curso transversal a todas las carreras de la Universidad Católica Andrés Bello, ${ }^{1}$ durante 1994-2014. En las primeras sesiones de dicha cátedra se ubicó al ser humano en medio de una pluralidad de los pareceres a lo largo de la historia. Con ello, se deliberaba sobre el hombre, su intento por comprenderlo desde diversas perspectivas de la historia de los conceptos (Begriffsgeschichte) y la prospectiva de los conceptos de la historia (Geschichtebegriffs).

Los paradigmas son tendencias del pensamiento humano que permiten analizar, comparar y sistematizar sus ideas y conceptos en diversos esquemas o modelos, con miras a definir y modelar al ser humano. Esta experiencia puede hacerse desde los naturalistas, los mecanicistas o los sistémicos. Otros, lo

Ejemplo del programa en la Escuela de Derecho. Véase: http://w2.ucab.edu.ve/ tl_files/Derecho/Archivos/Programas lerAno/Introduccion_al_Estudio_del_ 110 Hombre.pdf y el empleado en mi cátedra, disponible en http://w2.ucab.edu.ve/ tl_files/escueladeeducacion/planestudios/ comunes/00001_Introduccion_al_estudio_del_hombre.pdf plantearon desde los sociocríticos, los analíticos, los de-investigación (experimental, cualitativa), los interpretativos, los conductuales, los de tendencia emergente o contextual. No importa cómo se le denomine, el hombre establece o configura paradigmas ${ }^{2}$ desde la antigüedad, para explicar un conjunto de conocimientos y creencias que forman una visión del mundo (cosmovisión), en torno a una teoría hegemónica en determinado periodo histórico. Independientemente de la crítica que se realice a la obra de Thomas Kuhn, La estructura de las revoluciones científicas (1975), este estableció un enfoque particular en la filosofía de la ciencia, aún vigente. Los paradigmas se han hecho cada vez más complejos, ya que no actúan aislados, sino que interactúan en sí mismos con los demás. Los paradigmas surgen para determinar una percepción de la realidad. Los modelos paradigmáticos son metafísicos y epistemológicos, que proporcionan el "contexto" donde estos se forman, en los diferentes modelos teóricos, teorías, hipótesis y métodos que ofrecen directrices generales que imitan la organización del "mundo".

\section{Paradigmas}

Según se planteó anteriormente, en la ciencia se conceptualizó que un paradigma es un conjunto de realizaciones científicas "universalmente" reconocidas, que durante un tiempo proporcionan

\footnotetext{
2 Del griego $\pi \alpha \rho a ́ \delta \varepsilon \imath \gamma \mu \alpha$, parádeigma, modelo o ejemplo.
} 
modelos de problemas y soluciones a una comunidad científica. Estos modelos, como expone Thomas Samuel Kuhn (1975), tienden a complejizarse al encontrarse ante nuevos enigmas y anomalías. Estas últimas establecen las crisis que conducen a cambios y mejoras. Este proceso es incremental y trae consigo el progreso del saber humano, el cual, cuando una comunidad tanto científica, como religiosa o política da por sentado un paradigma, se crea un espacio-tiempo lineal donde nada cambia y establece una verdad factible e inmutable, y durante dicho lapso la evolución del conocimiento se estanca. Así, si este se comparte con otros especialistas, estos se convierten en sujetos activos de la ciencia y son quienes, al construir teorías científicas y contrastarlas con la experiencia, llevan a cabo observaciones y experimentos e intercambian entre sí información al respecto y críticas; producen, en definitiva, el mejoramiento del conocimiento (figura 1).

Un paradigma es lo que los miembros de una comunidad científica comparten y, recíprocamente, una comunidad científica consiste en hombres que comparten un paradigma.

[...] Bajo esta perspectiva, una comunidad científica está formada por practicantes de una especialidad científica. Han pasado por una iniciación profesional y una educación similar en un grado que no tiene comparación con la de la mayor parte de otros campos. En este proceso, han absorbido la misma literatura técnica y

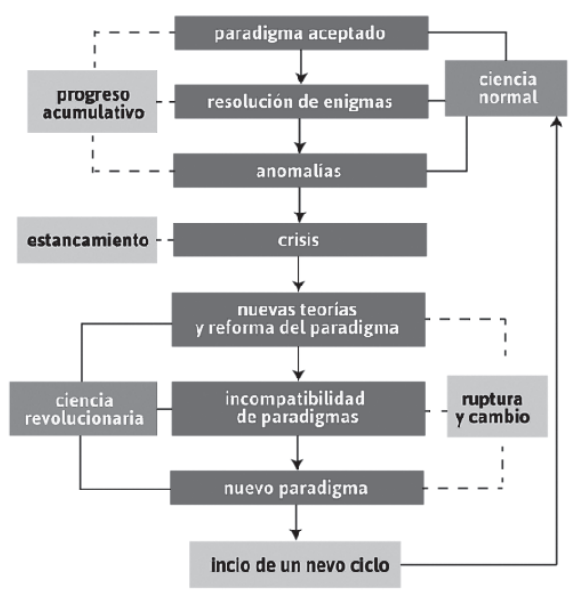

Figura 1. Ciclo propuesto en el desarrollo de algunos paradigmas según Thomas S. Kuhn

Fuente: Enciclopedia Herder.

desentrañado muchas de sus mismas lecciones. [...] Dentro de tales grupos, la comunicación es relativamente completa y los juicios profesionales, relativamente unánimes. [...] Por supuesto, existen en este sentido comunidades a muchos niveles. La más global es la comunidad de todos los científicos naturales. [...] Las comunidades de esta clase son las unidades que este libro ha presentado como las autorizadas y productoras del conocimiento científico (Kuhn, 1975, pp. 271-274). Si se comprende lo relativo del conocimiento y la necesidad de tener certeza, puede cuestionarse la vigencia y validez de esa interpretación "universal" en el "porvenir". De igual manera, el paradigma permitirá aproximaciones lineales o no, de una realidad con 
base en criterios, objetivos o compromisos. Así, el paradigma permite una estructura de factores y aspectos representacionales, convenidos de forma más o menos consciente, con la que un científico va en busca de su "objeto de investigación". Esto es otra de las críticas, ya que solo bajo ciertas condiciones particulares, este paradigma puede verificarse y replicarse. Así, el paradigma como modelo preteórico está configurado por: 1) las circunstancias del momento y lugar; 2) el estado en el que se halla la teoría científica, incluso de las otras disciplinas, y 3) los intereses que orientan el conocimiento.

La historia demuestra cómo los "objetos de conocimiento" pueden variar con la práctica científica y humanística que va tratando. Un paradigma es a menudo anticipación de una realidad deseada, no existente, pero futura. La confirmación de un paradigma, por tanto, se dictamina por el progreso del conocimiento y por el ulterior desarrollo de las relaciones sociales y políticas. Con el tiempo, los paradigmas del ser humano fueron adquiriendo complejidad funcional o socioestructural, ante la imbricación estructural del sistema social, es decir, la cantidad y la cualidad de las relaciones entre los elementos del sistema. Generalmente, con el grado de complejidad se mide el estado del desarrollo de una sociedad. Si crece la complejidad, aumenta la posibilidad de conflicto social, pero también la "capacidad de aprender" del sistema, en el sentido de que cambia más fácilmente y se adapta a necesidades tanto "externas", como "internas" (Luhmann, 1998).

\section{La complejidad}

El camino a la complejidad transcurre gradualmente en el tiempo, al irse ampliando el saber científico y la necesidad de algunos pensadores por descubrir, innovar y mejorar la comprensión de fenómenos e ideas vigentes en momentos y lugares particulares, ante las limitaciones del conocimiento. Desde la antigüedad, las prácticas del conocimiento se han enmarcado en alguno de los paradigmas del conocimiento imperantes (teocéntrico, antropocéntrico y policéntrico) (Schmidt, 2011) y las bases de conocimiento disponible.

Sin embargo, la ciencia de inspiración cartesiana iba muy lógicamente de lo complejo a lo simple; el pensamiento científico contemporáneo intenta leer la complejidad de lo real bajo la apariencia simple de los fenómenos. Esta aproximación comienza a debilitarse en la física ante la relación de indeterminación de Heisenberg o principio de incertidumbre (1925), ante la relación de la materia y la energía, lo que definió diferencias fundamentales entre física clásica y física cuántica. De hecho, con el tiempo se ha determinado que no hay fenómeno simple y su develamiento tiende a la complejidad. Sin embargo, este proceso del conocimiento que tiende a la complejidad ha sido "lento y cuesta arriba". Su lento emerger se debe en 
parte a la disciplinariedad aún vigente y al proyecto de la modernidad; la dificultad del manejo de múltiples variables, independientemente de los algoritmos y herramientas de cálculo, y a ser el centro de grandes debates y de grandes reflexiones, como ha sido el caso de la racionalidad con los debates entre Imre Lakatos y Paul K. Feyerabend o Karl Popper y Thomas Kuhn. La cientificidad y la falsabilidad son grandes debates de los que se habla, pero la complejidad nunca ha sido debatida.

La complejidad tiene un comienzo en el siglo XX; pueden citarse de manera sucinta los siguientes documentos clave: 1) Claude Shannon y Warren Weaver y su investigación Una teoría matemática de la comunicación (1948) en el Bell System Technical Journal; 2) Weaver, el mismo año, escribe Ciencia y complejidad, en el Scientific American; 3) John von Neumann y su multifacética obra, en especial su trabajo póstumo Teoría de los autómatas autorreproductivos (1966), abordan con una visión muy profunda esa cuestión de la complejidad de las máquinas, de los autómatas naturales en comparación con los autómatas artificiales; 4) Gaston Bachelard se refirió a esta en El nuevo espiritu cientifico (1934) y La formación del espíritu científico (1938); 5) Más tarde, lo anterior condujo a las teorías de la autoorganización, antes mencionadas, que son impulsadas por las investigaciones de Norbert Wiener en la Cibernética o el control y comunicación en animales y máquinas (1948); 6) W. Ross Ashby y N. Wiener entre 1948 y
1955 desarrollaron la teoría matemática de la comunicación y control de sistemas a través de la regulación de la retroalimentación (cibernética), que se encuentra estrechamente relacionada con la teoría de control; 7) Ludwig von Bertalanffy plantea la Teoría General de sistemas (1950), la que va difundiendo gradualmente entre especialistas de diversas disciplinas ;8) Heinz von Foerster en diversos escritos, particularmente en Sistemas de auto-organización y su entorno (1960) propone la aplicación del pensamiento cibernético en los procesos de autoorganización en sistemas sociales. La aplicación del pensamiento cibernético al propio pensamiento cibernético marcará el desarrollo de una cibernética de segundo orden: "observar nuestra propia observación y, en última instancia, dar cuenta de nuestro propio dar cuenta", la de los sistemas observantes (p. 92); 9) Herbert A. Simon, en Arquitectura de la Complejidad (2006), enfatiza el radicalismo tecnológico que marca el posthumanismo actual; 10) René Thom y E.C. Zeeman, en 1970, plantean la Teoría de las catástrofes, rama de las matemáticas de acuerdo con bifurcaciones en sistemas dinámicos, que clasifica los fenómenos caracterizados por súbitos desplazamientos en su conducta; 11) David Ruelle, Edward Lorenz, Mitchell Feigenbaum, Steve Smale y James A. Yorke en 1980 describen la Teoría del Caos, una teoría matemática de sistemas dinámicos no lineales que describe bifurcaciones, extrañas atracciones y movimientos caóticos, y 12) John H. Holland, Murray Gell-Mann, Harold 
Morowitz, W. Brian Arthur et al. en 1990 plantean el sistema adaptativo complejo, una nueva ciencia de la complejidad que describe surgimiento, adaptación y autoorganización. Así, hasta nuestros días, este concepto evoluciona de manera inter y transdisciplinar (Morin, 1994). Así se integran en el paradigma de la autoorganización las diversas teorías procedentes de diversas disciplinas que convergen por diferentes vías en torno a un nuevo concepto de orden.

Diversos científicos en la segunda mitad del siglo XX plantean la incertidumbre y lo azaroso de la vida y la ciencia. Edgar Morin (1994), en el pensamiento complejo, plantea la heterogeneidad, la interacción y el azar. Todo objeto del conocimiento, cualquiera que este sea, no se puede estudiar en sí mismo, sino en relación con su entorno; precisamente por esto, toda realidad es sistema, por estar en relación con su contexto o mundo. Morin establece algunos principios del pensamiento complejo: el dialógico, la recursividad, el hologramático. Así, el paradigma se constituye en una estructura mental y cultural desde el cual se mira la realidad. Estos paradigmas, por ser culturales, son inconscientes, son como un imprinting. En este aspecto se separa Morin de Kuhn, para quien los paradigmas son científicos, por tanto, conscientes. Con respecto al concepto de sujeto, Morin lo aplica a toda realidad 114 viviente, cualquiera que sea. El sujeto tiene tres características: su autonomía, su individualidad y su capacidad de "computar", es decir, de procesar infor- mación: "Ego computo ergo sum" dice Morin (1994); el hombre es el sujeto de mayor complejidad. Morin sostiene que no se puede asumir esta noción de sujeto desde un paradigma simplista. De allí la necesidad del pensamiento complejo; aquel "pensamiento capaz de unir conceptos que se rechazan entre sí y que son desglosados y catalogados en compartimentos cerrados" por el pensamiento no complejo. No se trata de repulsar lo simple, sino de percibirlo articulado con otros elementos; es cuestión de separar y enlazar al mismo tiempo. Se trata, pues, "de comprender un pensamiento que separa y que reduce junto con un pensamiento que distingue y que relaciona" (Morin, 1995).

\section{El ser-humano}

El Homo sapiens fruto de un proceso de hominización ${ }^{3}$ y sus ancestros, el Homo

3 Sobre los antecesores de las especies del género homo no hay acuerdo total entre los paleoantropólogos (es la reactualización del viejo tema del eslabón perdido), y actualmente se sostienen dos concepciones distintas. Una de ellas, la sostenida por el famoso paleoantropólogo Leakey, considera que debe existir un antecesor del Homo habilis a partir del cual se diferenció una rama paralela, la de los australopitecus que, según ellos, no serían antecesores del hombre. Pero otra teoría desarrollada actualmente (y reforzada con el descubrimiento en $1994-$ 95 del australopitecus ramidus por parte de Tim White), y formulada, entre otros, por T. White y Donald Johanson, sostiene que nuestro ancestro es el australopitecus afarensis, que a su vez provendría del australopitecus ramidus.Más recientemente, Meave Leakey ha descubierto el australo- 
erectus y Homo habilis) se ha distinguido de las demás especies animales de este mundo, ${ }^{4}$ según la clasificación de Carl Nilsson Linneo ven 1758. Aunque su nomenclatura biológica se vuelve hoy algo confusa ante una relativización de su concepción ante el cambio de valores, actitudes, creencias y conocimientos. Sin embargo, su sabiduría se fundamentó en su capacidad de usar el fuego y el desarrollo de herramientas.

El ser humano es el ser más desvalido y vulnerable en comparación con otros animales y seres vivos, con un desarrollo neurológico lento y sofisticado. Desde una antropología, Adolf Portmann (1948) y Arnold Gehlen (1980) calificaron al hombre como un ser desvalido, inacabado o de carencias. Al mismo tiempo, destacan la comunicación y el lenguaje como un constitutivo esencial del hombre, como ser abierto al mundo que se mueve con relativa seguridad en un hábitat donde estimulaciones y

pitecus anamensis, cuya antigüedad (unos 4,1 millones de años) lo hace anterior al australopitecus afarensis, pero no tan antiguo como el todavía controvertido australopitecus ramidus.

4 Sapiens significa "sabio" o "capaz de conocer", y se refiere a la consideración del ser humano como "animal racional", al contrario de todas las otras especies. Es precisamente la capacidad del ser humano de realizar operaciones conceptuales y simbólicas muy complejas — que incluyen, por ejemplo, el uso de sistemas lingüísticos muy sofisticados, el razonamiento abstracto y las capacidades de introspección y especulación — uno de sus rasgos más destacados (Wikipedia). respuestas guardan una correspondencia prefijada tenazmente por la evolución de la especie.

\section{El hombre que cuida el Edén y vive con el sudor de su frente}

El ser humano se caracteriza fenomenológicamente por su ser-activamente-en-el-mundo, y su cultura, trabajo y ocio tienen preferencia. La autorrealización puede ser un efecto formal de la praxis humana. Uno puede preguntarse: ¿el hombre tenderá más hacia el paradigma del Homo faber? Henri Bergson (1959), en su obra La evolución creadora (1907), apelando al mundo del trabajo, definió la inteligencia como "la capacidad de crear objetos artificiales, en particular herramientas para hacer herramientas, y de modificarlos de modo ilimitado" (1959, pp. 557 y 558). El hombre, dentro del contexto de su distinción entre instinto e inteligencia, supuso la capacidad de fabricar instrumentos o medios para diversos usos, y así estableció una característica esencial del ser humano. Su primer equivalente paleoantropológico sería el Homo habilis, y hay quienes lo relacionan con la especie Australopithecus Anamensis. ${ }^{5} \mathrm{Se}$ discute su antigüedad de entre cuatro a tres millones de años. Actualmente el

5 Especie encontrada en Kenia y descrita en 1995 por Meave Leakey (segunda esposa de Richard, del clan de los Leakey). El nombre de esta especie proviene de la palabra Turkana "nam", que significa "lago" y fue elegida en razón de la proximidad de Kanapoi al lago Turkana (Wikipedia). 
Homo habilis es considerado el primer hombre, caracterizado por ser el primer fabricante de útiles y organizador de su hábitat.

\section{El hombre que establece sus criterios y nombra las cosas}

En la Antigua Grecia, se empleaba la expresión del Homo mensura, frase que fue atribuida a Protágoras, y significa que "el hombre es la medida de todas las cosas". Esta frase ha sido interpretada de las más diversas maneras, pero parece claro que Protágoras se refiere al hombre individual, y usa el término "medida" (métron) en el sentido de criterio. Así, significaría que cada individuo humano es el criterio de lo que es, lo cual desemboca en un subjetivismo extremo que implica que no hay más realidad que las apariencias, que se manifiestan al hombre en la percepción. De esta manera, la percepción pasa a ser el criterio (particular) con que se rige el hombre, desaparece toda posibilidad de acceder a una imposible verdad e incluso se diluye la concepción misma de la physis (designa tanto el origen, como el desarrollo de cualquier cosa o proceso).

\section{El hombre que se desnaturaliza e individualiza}

Una de las expresiones más paradigmáicas corresponde a una frase de Plauto: Homo homini lupus, célebre en el contexto de la teoría política de Thomas Hobbes (1965), que la usa para calificar a la especie humana, ya que concibe a los hombres como átomos de egoísmo que, de no estar constreñidos por leyes que coaccionen su derecho natural, acabarían destruyendo la especie. Según Hobbes, hay dos postulados que fundamentan la ciencia política: 1) la cupiditas naturalis (la avidez natural) y 2) la ratio naturalis (razón natural).

Hobbes niega que los hombres sean "buenos por naturaleza". Para él, "toda asociación espontánea nace o de la necesidad recíproca o de la ambición, pero nunca del amor o de la benevolencia hacia los demás" (De cive., 1, § 14; Leviatán, 13). de manera que para Hobbes el origen de las sociedades no es ninguna pretendida bondad natural, sino el temor recíproco (Hobbes, 1965). A su vez, la causa fundamental de este temor es la igualdad de naturaleza entre los hombres (Hobbes proclama la igualdad natural humana), razón por la cual todos desean la misma cosa y, por tanto, el uso exclusivo de los bienes comunes.

El Homo homini lupus, en cuanto que todos son iguales, se plantea desde el punto de que todos tienen el mismo derecho sobre todo, incluida la vida de los demás (De cive., 1, § 14; Leviatán, 13). Ello, junto con la tendencia natural a perjudicarse mutuamente, origina, en el estado de naturaleza, un estado de guerra incesante de todos contra todos, en la que el hombre es el peor enemigo para el hombre, situación que hace pensar que los hombres son más parecidos a los lobos que a las abejas. Evidentemente, en este estado de naturaleza no puede 
hablarse de justicia (ni de injusticia), ya que esta solo surge con la ley, la cual es fruto de un pacto común. No obstante, puesto que el derecho es la libertad de usar las propias facultades según la razón, a menos que esta sea capaz de hallar un medio mejor, la guerra de todos contra todos es la condición natural (y legítima) en el estado de naturaleza. Pero, puesto que dicha guerra de todos contra todos desembocaría en la destrucción total de la humanidad, dicho estado debe ser superado, ya que la mera amenaza de dicha pugna compartida entre todos impide toda actividad económica y toda previsión. Así, no sería posible ni el comercio, ni la industria, ni la agricultura, ni la ciencia o el arte, y el hombre seguiría estando al nivel de los animales (Leviatán., 13; De cive, 1, § 13).

\section{El hombre que se difumina en el mundo}

Así, el hombre parece desvanecerse. En el seno de las ciencias humanas emerge, durante el siglo XX, una serie de nuevas formas de saber, cuyo rol resulta decisivo ya que en ellas se realiza la experiencia de un pensamiento en el vacío del hombre desaparecido, propuesto por M. Foucault, en la sección final de Las palabras y las cosas (1968). El psicoanálisis y la etnología constituyen dos ejemplos de estos nuevos conocimientos, cuya característica principal es conducirse por un principio perpetuo de inquietud que les dirige directamente a esa zona movediza que las ciencias humanas pretenden desconocer: los límites exteriores donde el hombre se disuelve (Foucault, 1968, p. 362).

Nietzsche sería el precursor de esta reflexión contemporánea. Su filosofía inauguraría el desarraigo de la antropología al señalar la relación de fondo entre Dios y el hombre que hace de la muerte del primero un acontecimiento equivalente a la desaparición del segundo. La muerte de Dios es su propia muerte y la de todas aquellas imágenes que le son correlativas.

De hecho, cuando el hombre es entendido como sujeto de su propia conciencia y de su propia libertad, encarna en cierto modo la figura del Dios perdido. Foucault, al igual que Nietzsche, observa esta metamorfosis de la idea de Dios en el pensamiento del siglo XIX y la describe como una teologización del hombre (Foucault, 1991). Así, el nacimiento del hombre es algo muy reciente: aparece en la edad clásica, cuando se apaga la transparencia del discurso. La finitud del hombre reemplaza la infinitud de Dios. Foucault sostiene, casi descaradamente, que antes del siglo XIX el hombre no existía.

Este nacimiento implica también una muerte inevitable. La muerte del hombre, según Foucault, es epistemológica: el hombre morirá como sujeto, como agente de la historia. Foucault propone, de cierta manera, una historia de los modos de ser del lenguaje. El hombre aparece cuando el discurso se apaga, y el hombre morirá cuando el ser del lenguaje reaparezca. 


\section{Del hombre creatura divina al hom- bre trastornado}

Para valorar este cambio en la historia del pensamiento bastarán unas pocas indicaciones en el contexto del siglo XXI, donde el individualismo conduce a estas posturas poco humanas. La cuestión acerca del hombre es ciertamente en algún modo "el" tema de la filosofía; sin embargo, en tiempos pasados no constituyó el punto dominante. La antigüedad giraba en torno al cosmos o la naturaleza que descansaba sobre sí misma, considerando al hombre en conexión con ella. Para la Edad Media el hombre fue un miembro del "orden2 salido de Dios. En la Edad Moderna, el hombre se ubicó en otras categorías, y se colocó incluso sobre sí mismo. El ser humano, "sujeto" se vanagloria como "sujeto trascendental" y se olvida su "sujeto inmanente". De manera análoga, su ser racional olvida su ser emocional. Se hace necesario evitar el reduccionismo del ser.

El hombre cayó, al fin, en la cuenta de la inanidad de tales construcciones, advirtiendo que lo había perdido todo, incluso su propia personalidad; que había sacrificado la vida al concepto abstracto ilusorio y que se encontraba ahora ante la nada.

El renacimiento empezó al verse arrojado sobre sí mismo y (en oposición al idealismo) precisamente sobre la concepción personal e histórica concreta de su vida, que se adelantaba y desbordaba todo concepto. Así, deviene el hombre mismo tema único del filosofar: se trata de estudiarlo y considerar en él todo lo demás. Por eso la filosofía se hace más o menos antropología, por más que, a veces, se pierde también en ella. Las primeras manifestaciones se dan en el Schelling del poster periodo y en Kierkegaard.

Las diversas direcciones de la antropología muestran al mismo tiempo los peligros que dentro de sí oculta. Si la vida pasa a primer término, considerándola predominantemente desde el punto de vista del cuerpo, la naturaleza propia del hombre se desvanece; esto es lo que se percibe en Nietzsche; se advierte reiteradamente en la filosofía de la vida y aparece sobre todo en el Scheler de los últimos años y en Klages.

Las más de las veces, se llegan a volatilizar en la vida los demás contenidos por las vías del biologismo, relativismo y psicologismo. Esto no afecta a Teilhard de Chardin (1999), que consuma la biósfera mediante la noosfera (del espíritu). Otros destacan el carácter privativo del hombre que, como existencia (Existenz), lleva por su autorrealización ventaja a todo mero existente (Vorhanden). Sin embargo, aun en estos se nota siempre la inclinación a reducirlo todo (de las relaciones humanas, especialmente la unión con Dios) a puros modos de existir del hombre. El humanismo de Sartre nos brinda un ejemplo, y tampoco está totalmente libre de ello la trascendencia en Jaspers; esta actitud cambia la antropología en antropologismo. 


\section{El hombre desde su existencia}

El hombre como sujeto aislado queda superado mediante el "ser-en-el mundo" de Heidegger y más tarde mediante su "exigencia del ser. Buber, entre otros, añade el diálogo, del "ser-para-la-vida", apenas insinuado en Heidegger como otro factor decisivo. La antropología marxista de Bloch (2004) arroja de nuevo al hombre hacia sí mismo, por cuanto su esperanza permite ciertamente un trascender, pero no una trascendencia. Vemos una raíz importante de los peligros mostrados en aquel método que no quiere trascender la autoexperiencia inmediata de la vida o del hombre, lo que permite solo la interpretación o hermenéutica (Dilthey), o bien el análisis fenomenología (Husserl) de esta, sin progresar hacia una verdadera fundamentación trascendental-metafísica.

\section{Un hombre que pretende ser lo que-no-es}

El ser humano es el resultado de su actuar; como productor vive en un entorno que él mismo ha creado, un mundo que ha construido con su trabajo, donde no solo la naturaleza en general es transformada para obtener el artificio humano, sino que también su propio cuerpo es objeto de toda clase de manipulaciones y alteraciones, incluyendo las técnicas actuales que transforman su apariencia exterior. Durante los años 50 del siglo $\mathrm{XX}$, fue usado por la teórica de la política Hannah Arendt (1958) para enfatizar la capacidad humana de controlar su entorno con el uso de herramientas. También fue utilizado en el mismo sentido por el escritor Max Frisch en su novela Homo faber (1957). En los años siguientes, el hombre hizo del trabajo una teleología, un fin de vida; el hombre nace para trabajar y transformar al mundo. Así, se convierte en un adicto del trabajo (workholic); por tanto, no debe extrañar que se comenzara a hablar a mitad del siglo XX del Homo laborans o el animal laborans (Arendt, 1958) y del Homo œconomicus (Persky, 1995).

Desde el Homo faber y el animal laborans se estableció una conformación de los espacios comunes y una construcción de la identidad del hombre. Para ello, hay que distinguir las características del trabajo, desde la perspectiva arendtiana, donde la instrumentalidad y permanencia sobresalen en la artificialidad del mundo, así como su impacto en la manera como se relacionan los seres humanos).

El hombre de Karl Marx, en El Capital (1867) adquiere las mismas connotaciones de la frase de Benjamín Franklin: "el hombre es el animal que hace herramientas". Pero este problema se agrava, pues la representación teórica se comportaría de forma racional ante estímulos económicos, siendo capaz de procesar adecuadamente la información que conoce y actuar en consecuencia. El término hombre económico fue utilizado por primera vez en el siglo XIX por los críticos de la obra de John Stuart Mill sobre economía política. Debajo hay un pasaje del trabajo de Mill al que se referían esos críticos decimonónicos: 
La economía política no trata la totalidad de la naturaleza del hombre, modificada por el estado social, ni de toda la conducta del hombre en sociedad. Se refiere a él sólo como un ser que desea poseer riqueza, y que es capaz de comparar la eficacia de los medios para la obtención de ese fin" (Mill, 1836, s. p.)

\section{El hombre lúdico y homicida protegido}

El hombre tiene una naturaleza azarosa y lúdica, luego, ¿se podría decir más bien que el ser humano tiende al Homo ludens (Huizinga, 2005) o al Homo sacer (Agamben, 1995)? Se pone en tapete la categoría del juego. Posiblemente, Johan Huizinga sea el primero en abordar el fenómeno lúdico desde una perspectiva antropológica, es decir, en el plano científico y académico. Tras recorrer la prehistoria y adentrarse en la historia, el autor sostiene que la cultura, en sus diversas etapas y manifestaciones, surgió en forma de juego o, para ser más preciso, "en las formas y con el ánimo de un juego". Con esto quiso decir Huizinga que ella se desarrolló "en el juego" y "como juego", de manera que lo lúdico subyace en los fenómenos culturales. Huizinga sostiene que "las formas superiores de juego" son las sociales, dentro de las cuales identifica una amplia gama de actividades de la cultura que van desde la poesía hasta las reglas de la guerra, el derecho, el arte y la política. Todas ellas sometidas a la competición lúdica, en la que los impulsos competitivos y los afanes de triunfo del hombre se ponen de manifiesto. Pero la competición lúdica no solo es individual, sino también colectiva, o sea entre grupos, pueblos y naciones. Este planteamiento se complementará con el de Sartori (1998).

En paralelo con lo anterior, se retoma la figura del Homo sacer que se ha puesto en el centro del eje de la discusión filosófica, jurídica y política a partir de la apreciación de Giorgio Agamben. Si bien es cierto que se ha trabajado con esta figura en el derecho romano, en reiteradas oportunidades, y se ha discutido acerca de la ambivalencia del significado del sacer desde ciertos mitologemas científicos, también es verdad que la relevancia y los matices que nos ha mostrado Agamben a partir de su texto han sido reveladores. En 1995, publicó un texto dedicado a la reflexión sobre esta figura que lleva por título Homo sacer. El poder soberano y la nuda vida (Il potere soverano e la vita nuda. Homo sacer I) y remite al texto Sobre la significación de las palabras en el que Festus vincula por primera vez el carácter de la sacralidad a una vida humana. El texto de Sextus Pompeius Festus dice:

Pero se le da el epíteto de sacer al hombre que el pueblo ha juzgado por un delito; no está permitido sacrificarlo pero el que lo mata no es condenado como homicida puesto que la primera ley tribunicia establece esta disposición: 'si alguien mata a 
aquel que es sagrado por plebiscito, no será considerado homicida. De allí que en el lenguaje familiar se llame sacer a todo hombre malo e impuro'. (citado en Novus, 17 de agosto de 2010, s. p.)

En contraparte, en estos tiempos de incremento de los niveles de agresión humana y antropogénica, el Homo sacer se constituye en un paradigma en el que el individuo ha sido juzgado por el pueblo debido a un delito cometido por él, pudiendo darle una muerte cualquiera sin ser considerado homicida. Agamben ha desarrollado el Homo sacer desde diversas situaciones padecidas en las últimas décadas del siglo XX; es aquel que se encuentra más allá, entre la vida y la muerte, suspendido en la esfera del soberano que puede decidir quién puede ser asesinado sin considerarse delito. La inviolabilidad de la vida, por tanto, se define, como asegura Giorgio Agamben en su obra mencionada: Homo sacer. El poder soberano y la nuda vida, y remite al texto Sobre la significación de las palabras destaca a su vez la impunidad de matar y la exclusión de sacrificio.

El ser humano es el único animal que busca prestigio y que afronta peligros, emprende tareas y asume riesgos para alcanzarlo. La lucha por el prestigio - y cada cultura tiene su propia noción del prestigio-siempre condujo al hombre a acometer acciones románticas, aventuras riesgosas y cruentos combates, muchas veces irracionales.

\section{El hombre mediocre, simplificador y de pensamiento cortoplacista}

Desde otro punto de vista, sobre todo por su quehacer diario: ial Homo light: Homo videns (Sartori, 1998), o al Homo communicans et movilis (De Matteis, 1995, citado en Sartori, 1998)? Cuando se habla del Homo videns, se habla de un individuo ligeramente (limitado o deliberadamente) enterado de lo que le rodea. El Homo simonianus supone la reducción de la complejidad del razonamiento humano a la simplicidad del "pensamiento" binario bajo el que opera la computadora, como si nosotros mismos fuésemos en el fondo y en última instancia ese Homo computacional que vive y existe esencialmente para colectar, procesar y transmitir información (Newell y Simon, 1972). Se trata de una visión que desnaturaliza el comportamiento humano para apreciarlo como comportamiento artificial, como esa capacidad de almacenamiento y cómputo que indique al hombre los términos de "su decisión". Desde esta perspectiva, las ciencias de lo artificial tendrían que dedicarse no solo a investigar todo lo que se relaciona con los sistemas artificiales creados por el hombre, sino también a comprender las maneras como tales sistemas recrean al hombre mismo a imagen y semejanza de los sistemas artificiales, amenazando su propia existencia. Esta paradoja de la modernidad artificial se dibuja en el tercer nuevo milenio ante las tendencias de la poshumanidad. En este sentido, es indispensable reconocer y debatir sobre los fundamentos del pensamiento 
de Simon para comprender el comportamiento humano en su jaula de hierro artificial.

El hombre de hoy es un sujeto relativamente informado, y con una educación humana que rasguña la mediocridad y la miseria; muy entregado al pragmatismo, por una parte, y a bastantes tópicos, por la otra. El Homo videns tiene interés por todo, le seduce cualquier cosa, aunque es notable su desinterés por la sociedad que lo circunda. Determinado por las imágenes, el hombre solo está apto para creer aquello que ve, y así aniquila toda información abstracta (invisible), lo que provoca en él la falta de racionalidad.

Este Homo videns vive con un dispositivo en la mano y haciendo zapping, colmado de confort y bienestar, un auténtico hombre de plástico, sin una escala de valores sólida y sumergido en el consumo, descreído de casi todo lo que lo rodea, ambiguo en sus pensamientos y juicios, que a menudo cambia de parecer; es "un ser humano rebajado a la categoría de objeto". Pasa a ser simplemente un animal simbólico lejos, muy lejos, del Homo sapiens-sapiens. Según expresa Giovanni Sartori (1998):

El contraste que estoy perfilando entre homo sapiens y, llamémoslo así, homo insipiens no supone idealización 122 alguna del pasado. El homo insipiens (necio y, simétricamente, ignorante) siempre ha existido y siempre ha sido numeroso. Pero hasta la llegada de los instrumentos de comunicación de masas los «grandes números» estaban dispersos, y por ello mismo eran muy irrelevantes. Por el contrario, las comunicaciones de masas crean un mundo movible en el que los «dispersos» se encuentran y se pueden $<<$ reunir $>>$, y de este modo hacer masa y adquirir fuerza. En principio va bien; pero en la práctica funciona peor. Y aquí sobre todo entra en juego Internet, que abre un nuevo y gigantesco juego. Pues las autopistas de Internet se abren, mejor dicho, se abren de par en par por primera vez especialmente a las pequeñas locuras, a las extravagancias y a los extraviados, a lo largo de todo el arco que va desde pedófilos (los vicios privados) a terroristas (los flagelos públicos). Y esta apertura es más significativa en tanto en cuanto el hombre reblandecido por la multimedialidad se encuentra desprovisto de elementos estabilizadores sin raíces «firmes». Así pues, aunque los pobres de mente y de espíritu han existido siempre, la diferencia es que en el pasado no contaban -estaban neutralizados por su propia dispersión- mientras que hoy se encuentran, y reuniéndose, se multiplican y se potencian (s. p.).

\section{El hombre alienado, codicioso y doliente}

La afanosa búsqueda de una "calidad de vida" ha llevado al hombre a aburguesarse, como diría Alain Benoist (2007). 
Hoy en día, tanto de las tendencias de derecha como de las de izquierda, los hombres anhelan apertrecharse de dinero como nunca (Homo avarus), ya sea desde el Homo politicum en vez del Homo civilis. Lo cierto es que el Homo sapiens-sapiens de hoy se debate más en la dimensión ético-técnica como Homo technicans, aunque me acerco más a la ejemplificación de Edgar Morin: como Homo demens:

A partir de entonces, aparece el semblante del hombre oculto bajo el emoliente y tranquilizador concepto de sapiens. Se trata de un ser con una afectividad intensa e inestable, que sonríe, ríe, llora, ansioso y angustiado, un ser egoísta, ebrio, estático, violento, furioso, amoroso, un ser invadido por la imaginación, un ser que conoce la existencia de la muerte y que no puede creer en ella, un ser que segrega la magia y el mito, un ser poseído por los espíritus y por los dioses, un ser que se alimenta de ilusiones y de quimeras, un ser subjetivo cuyas relaciones con el mundo objetivo son siempre inciertas un ser expuesto al error, al yerro, un ser úrico que genera desorden. Y puesto que llamamos locura a la conjunción de la ilusión, la desmesura, la inestabilidad, la incertidumbre entre lo real y lo imaginario, la confusión entre lo objetivo y lo subjetivo, el error y el desorden, nos sentimos compelidos a ver al homo sapiens como homo demens. (Morin, 1994, p. 131)
El ser humano vive alienado ${ }^{6}$ por diversas razones (política, económica, tecnológica, ideológica, religiosa o sexual). La alienación, en sentido filosófico, corresponde a las palabras alemanas entfremdung, veräusserung y entäusserung, que significan "extrañación", "distanciamiento" y "exteriorización2, y expresan una extrañeza del sujeto respecto de sí mismo. El sentido filosófico de la noción de alienación ha sido elaborado en la actualidad especialmente por Hegel, Feuerbach y Marx. Sin embargo, este concepto de alienación individual y colectiva, ya en la filosofía del siglo XVIII, aparecía para referirse a las situaciones de un ser-humano que depende de-otro(s). Así, Rousseau identificaba alienación con socialización mal realizada, que debe reemplazarse por una transformación de la independencia natural del hombre en libertad política, gracias a la cual el hombre, convertido en ciudadano, esté plenamente integrado en la sociedad. La alienación surge cuando

6 Término de origen jurídico derivado del latín alienus, ajeno, que pertenece a otro (alien), y que se aplica en las ventas o cesiones. Así, alienar un bien equivale a regalarlo o a venderlo, es decir, transmitir a otro algo que era propio. Por extensión se habla también de alienación en un sentido psicopatológico, como sinónimo de pérdida de juicio o locura. El alienado es, entonces, el enfermo mental cuya mente está escindida. Estas formas de alienación suponen también un extrañamiento o alejamiento del que se aísla respecto de una norma o de la sociedad. 
la realidad espiritual aparece como objeto, originando la naturaleza, cuya objetividad debe superarse (Aufhebung) dialécticamente, mediante la apropiación del mundo por parte del espíritu; prácticamente, por medio del trabajo o, teóricamente, mediante el arte, la religión o la filosofía.

De esta manera, al proceso de exteriorización o alienación ha de corresponder otro en sentido inverso de recuperación de lo alienado, de reconciliación del espíritu consigo mismo. El hombre tendrá que reconocer, por ejemplo, que el mundo de la cultura ha sido un producto necesario de la naturaleza humana, pero que, una vez creado, se ha distanciado del hombre y ha logrado dominarlo.

Al hombre le toca reconocer el dominio de algo que él mismo ha creado y buscar la reconciliación con la cultura, y hacer que esta sea verdaderamente humana. Por ello, toda sociedad en la que los hechos vayan por un lado y los valores por otro es una sociedad alienada y no reconciliada consigo misma. Adicionalmente, está el acoso, que corresponde a una serie de comportamientos coactivos y ofensivos que se ejercen desde alguien que tiene o realiza algún poder sobre otra persona vulnerable, para intimidarlo, desmotivarlo, amedrentarlo o, incluso, conseguir que deje de cumplir con sus responsabilidades. Además de la sociedad, esto supone mucho más que la mera tolerancia o el reconocimiento, puesto que "se hace cargo también de lo alienado, lo débil, lo culpable y lo caduco de la otra per- zona" (Scherer y Giles 1979, pp. 130).

Algunos autores como Martin Buber, en sus obras de Yo-Tu (Ich und Du, 1923) destaca la importancia del diálogo y de las relaciones interpersonales y en ¿Qué es el hombre? (Das Problem des Menschen, 1943), la finitud, soledad e integralidad del ser, en cuya dialógica, en cuyo estar-dos-en-reciproca-presencia se realiza y se reconoce cada vez el encuentro del "uno" con el "otro". En Lévinas (1977) han visto la interpersonalidad humana como una tensión que afirma la trascendencia absoluta del otro. Para Buber, el auténtico encuentro interpersonal tiene lugar cuando el yo y el tú se captan recíprocamente, de modo que uno tiene en cuenta la situación del otro y reafirma su alteridad. Incluso la auténtica conciencia reflexiva de la propia "yoidad" solo es posible en la captación de la alteridad del otro por cuanto que es otro (figura 2).

Con el Homo sapiens, como plantease Linneo, ya el ser humano no solo se distingue únicamente del resto de animales por su inteligencia, sino también por el vigor destructivo de su violencia. Según expresa Johannes A. Von Horrach (2013):

El demens del hombre es el reverso del sapiens, pues ambos se encuentran conectados directamente, y la dialéctica de opuestos no es capaz de resolverse en favor de ninguno de los dos extremos. No hay punto final a la incertidumbre potencial que caracteriza a lo humano. 




Figura 2. Representación parcial de los diversos paradigmas sobre el hombre

Fuente: elaboración propia.

La conciencia de la muerte es el momento fundamental, pues supone una ruptura decisiva, un desgarramiento traumático con la inmediatez tranquila de la existencia que caracteriza al resto de especies animales. A partir de la certeza de que toda vida es perecedera, la finitud se impone como atributo fundamental de lo existente, con el añadido de que lo humano siempre se ha negado a aceptar esta finitud, y en gran parte todo proyecto cultural siempre ha ido encaminado a erradicar esa certeza bajo el peso de construcciones suprasensibles con vocación de continuidad. Surge así, por ejemplo, la idea de inmortalidad, articulada por el mito y la magia. Pero todo son vanos intentos de suturar la 'escisión originaria' (Hölderlin), la que desfonda toda pretensión de construir identidades fuertes. Desposeído de verdad, el mundo del devenir se idealiza y trascendentaliza, pero el proyecto mismo de sustentación de esa realidad artificial sólo puede mantenerse sobre la clausura, la exclusión y la expiación. A falta de verdad, se impone la necesidad de identidades fuertes, omnicomprensivas y que escapan artificialmente a toda incertidumbre. 
El demens surge con especial virulencia en esta estrategia de búsqueda de una verdad trascendental; ninguna identidad con vocación de absoluto puede sustentarse si no es apelando al fondo de violencia excluyente e idolátrica que anida en lo humano. De esta forma, todo intento de afirmación de algo implica también directamente su doble, la negación de lo que queda fuera de la selección, necesario para que la afirmación pueda llevarse a cabo.

Fruto de la conciencia de lo escindido, el hombre es un ser devorado por la ansiedad, la crisis y la neurosis. Su existencia se convierte en un proceso agónico para articular una identidad que proteja al sujeto de la devastadora realidad presidida por la certeza de la finitud. Su negación trascendental de la muerte lo conduce a la creación de un mundo imaginario poblado de dobles, fantasmas, dioses, ángeles, demonios, culpables, etc. El hombre no asume la realidad de la muerte, pero al mismo tiempo la conciencia intrínseca de la inminencia permite la existencia como hombre, como homo sapiens (demens). (citado en Ramírez González, 2013, s. p.)

\section{El Homo productor y bioeticus}

El Homo productor y bioeticus son modelos

126 con una dimensión más técnica o práctica. Aquí se busca integrar el desarrollo del "espíritu" como dimensión humana diferenciadora de los demás seres vivos, a través de una connotación más holística y se denominó el paradigma del Homo productor (Schmidt, 1994) o el Homo bioethicus (Mainetti, 2002).

El Homo productor, sin dejar de ser Homo sapiens, es un ser que tiene una sensibilidad y capacidad especial de recibir y dar, de razonar y que lleva por delante, en su sentido literal, el ser que sabe y el ser que produce. Un ser que vive un momento y un lugar particular, en el cual el mundo se transforma y es capaz de facilitar o liderar dichos procesos de cambio. Por otro lado, hay que comprender hoy como modelo cosmopolita al Homo bioethicus, el hombre bioético, responsable del nuevo orden vital. ${ }^{7}$

La tecnociencia parece orientada por un deseo antropoplástico o voluntad demiúrgica, pues tiene capacidades para fabricar o remodelar al hombre, capacidades exclusivamente divinas en la tradición religiosa. Algunos teólogos hablan de que el hombre está "jugando a Dios", y el imaginario social registra a Zeus en el Olimpo lanzando sus flechas para castigar a la osada criatura que peca de hybris manipulando la vida en el laboratorio o alumbrando formas superiores de inteligencia. ${ }^{8}$ Estos

$7 \quad$ Recuérdese la tipología humana de la Geisteswisenchtaftliche Psychologie según E. Spranger (Lebensformen, 1914), que describe al hombre teorético, al estético, al religioso, al político y al económico

8 Sobre el argumento de "Playing God" en la arena bioética de nuestros días, véase Splicing Life. The social and Ethical Issues of Genetic Engineering with Human Beings. President's Commission for the Study of 
paradigmas buscan complementar las reducciones paradigmáticas anteriores con una visión holística y compleja. El ser que-produce, en beneficio de los-demás y de la naturaleza. Como expresa Mainetti (2002):

Pinocho representa al homo bioethicus en un grado superior al del hombre biogenético y al del hombre cibernético, pues como nos enseña esta tierna historia, el ser humano no se deja reducir a la vida ni al artificio, a la bestia o a la máquina, aunque tiene natural vocación por una y otra alternativa. La manipulación técnica encuentra entonces sus límites en la naturaleza simbólica del hombre, en la "construcción" del cual la diferencia del signo y la técnica plantea los más delicados y acuciantes problemas bioéticos. ${ }^{9}$

El hombre es fundamentalmente un ser de cultura, de educación permanente, y esa cultura y educación tienen como meta el desarrollo de la conciencia moral, la ciencia del bien y del mal, con la que la humanidad no se ha reconciliado desde el pecado primigenio y la pérdida del paraíso. (s. p.)

Ethical Problems in Medicine and Biomedical and Behavioral Rescarch (noviembre de 1982).

9 Cf. Hottois (1990), donde se dan comunes ejemplos que "muestran claramente la diferencia entre las manipulaciones simbólicas del ser humano, manipulaciones internas a la esencia natural-cultural del hombre, y las intervenciones tecnocientíficas vivenciadas como extrañas a esta esencia y por ello vergonzantes" (pp. 70-75).
Al hablar del Homo sapiens y del Homo productor, se hace referencia al ser humano como un ser que tiene la capacidad de recibir y dar, de razonar y de lleva por delante. O expresado de otra manera, en su sentido literal expresa: el ser que sabe y el ser que produce. Un ser que vive un momento y lugar particular, en el cual el mundo se transforma.

El homo productor debe saber superar los escollos de las coyunturas que se presentan en estos tiempos; en las primeras décadas del siglo XXI se caracterizarán en una constante dependencia de la tecnología, la urbanización intensiva y extensiva, la burocratización oficial y las estructuras más planas en las empresas privadas, la politización y masificación de las comunidades.

\section{El Homo contemplans tradensque}

Para concluir, en la dimensión humanística, espiritual e integral se plantea al Homo contemplans tradensque (Schmidt, 1992), el cual es la utopía del ser humano, una persona análoga al perfil de Jesús de Nazaret, cuyo perfil marca a grandes personalidades del mundo, creyentes o no, y al cual busca asemejarse como proyecto de vida. Tal vez, el mismo hecho de que diversos pensadores disertasen sobre la naturaleza humana debe hacernos pensar en su multiforme concepción y que en realidad esta se desarrolla más en la dimensión ético-técnica y que encarna al Ens capax amoris (Schmidt, 2012). 
El ser humano, además de ser racional, es un ens capax amoris. La creación de esta civilización es una posibilidad real del ser humano, en la medida en que desea amar y ser amado, y es capaz de ampliar el concepto de razón instrumental, e integrar en su seno la razón comunicativa y la razón cordial.

Según Marcel Mauss (1968), existe una intima relación entre progreso social y lógica del don. El dar y el recibir forman parte del progreso social y económico de un pueblo. Escribe el investigador francés:

Entonces, ¿qué nos vamos a encontrar al final de esta investigación? Las sociedades han progresado hasta el punto de que ellas mismas, sus subgrupos y, finalmente, sus individuos, fueron capaces de estabilizar sus relaciones, dar, recibir, y finalmente superarse. Fue entonces cuando nos las arreglamos para intercambiar bienes y personas, no sólo de un clan a otro clan, sino de unas tribus a otras tribus y de unas naciones a otras naciones, especialmente de un individuo a otro. Así y sólo entonces, la gente será capaz de crear intereses mutuamente satisfactorios, $y$, finalmente, defender sin tener que recurrir a las armas. Así, el clan, la tribu, la gente conoció que para que el futuro de nuestra civilización sea factible, está en saber que sin la 128 matanza de los opuestos y el dar sin sacrificar el uno por el otro. Este se constituyó en el secreto permanente de su sabiduría y su solidaridad. (p.

105) (traducción del autor)

El ser humano, como ens rationale, es capaz de calcular, anticipar y programar, pero no solo en beneficio propio o de su grupo de interés, sino también en beneficio de todos. La lógica del don es, ante todo, lógica y no un movimiento irracional. Darse no es contradictorio con la naturaleza humana, ni con la racionalidad. La razón, fecundada por el principio de gratuidad eleva la facultad de pensar a sus máximos horizontes y hace al ser humano apto para dar más y mejor, para dar lo mejor de sí mismo a los otros.

Todo paradigma arrastra siempre consigo una determinada imagen del hombre, que incluye las notas básicas que delimitan su naturaleza, un ideal de humanización, una concepción del sentido de la existencia y alguna postura frente a su destino último. Las ideas del hombre presentes en nuestro mundo son múltiples y tienen perfiles algo vagos, pues no suelen ser resultado de una antropología explícita y bien elaborada. Para el humanismo parece bastar con una idea genérica que mantenga algún tipo de originalidad en el ser humano frente al resto del cosmos, pero, más allá de ese mínimo, sus contenidos aparecen como difusos y difíciles de apresar. A pesar de estas y otras dificultades, tampoco es cuestión de ignorar que la marea de lo inhumano crece día a día, y mucho menos de despreocuparse o resignarse ante su avance. Lo cierto es que no parece 
que hoy tengamos ninguna respuesta satisfactoria a esta cuestión y tampoco parece fácil adivinar con cierta seguridad cuál sería el camino para obtener una respuesta válida para el siglo XXI.

\section{Referencias}

Arendt, H. (2013). Diario filosófico (19501973). Barcelona: Herder.

Benoist, A. (2007). Demain, la décroissance! Penser l'écologie jusqu'au bout. París: Edit.e

Bergson, H (1959). La evolución creadora. En Obras escogidas (pp. 602-605). México, D. F.: Aguilar.

Bloch, E. (2004). El principio esperanza (Trad. F. González Vicén). Madrid: Trotta.

Buber, M. (1995). Caminos de utopía. México, D. F.: Fondo de Cultura Económica.

Buber, M. (1998a). Ensayos sobre la crisis de nuestro tiempo. Buenos Aires: Milá.

Buber, M. (1998b). Yo y tú. Barcelona: Claret.

Buber, M.artin (1984). ¿Qué es el hombre? Madrid: Fondo de Cultura Económica.

Festus, S. P. De verborum significatu, "Sacer Mons". En De verborum significatu quae supersunt com Pauli epitome. Edidit Aemilius Thewrewk de Ponor. Pars 1 Recuperado en https://archive. org/stream/deverborumsignifoofestuoft/ deverborumsignifoofestuoft_djvu.txt (01/01/2017).

Frisch, M .(1983). Homo faber. Frankfurt: Suhrkamp.

Foucault, M. (1991). Saber y verdad. Madrid: Ediciones de La Piqueta.
Foucault, M (1968). Las palabras y las cosas. Una arqueología de las ciencias humanas (E. C. Frost, Trad.). París: Buenos Aires: Siglo XXI.

Hernández, I. (2002). El Homo faber de Max Frisch como punto de partida para el desarrollo de nuevos modelos en la literatura suiza. Revista de Filología Alemana, 10, 179-204.

Hobbes, T. (1965). De cive.,I, 2. Antología: Del ciudadano. Leviatán. Madrid: Tecnos.

Hottois, G (1990). Le paradigme bioéthique. Une éthique pour la technoscience. Bruxelles: De Boeck Université.

Huizinga, J. (2005). Homo ludens. El juego y la cultura. México, D. F.: Fondo de Cultura Económica.

Kuhn, T. (1975). La estructura de las revoluciones científicas. México, D. F: Fondo de Cultura Económica.

Luhmann, N. (1998). Complejidad y modernidad: de la unidad a la diferencia. Madrid: Trotta.

Mainetti, J. A. (2002). Homo bioethicus II. Bioetica Ficta (2). Recuperado de http:// elabe.bioetica.org/13.htm

Mauss, M. (1968). Essai sur le don. Forme et raison de l'échange dans les sociétés primitives. París: PUF.

Marx, K. (1990). El Capital. Crítica de la economía política. En F. Canals (Ed.), Textos de los grandes filósofos: edad contemporánea. Barcelona: Herder.

Mill, J. S. (1836). On the definition of political economy, and on the method of investigation proper to It. London and Westminster Review.

Morin, E. (1994). Epistemología de la complejidad. En D. F. Schnitman (Ed.), 
Nuevos Paradigmas, Cultura y Subjetividad (pp. 421-42). Barcelona: Paidós.

Morin, E. (1995). Las reorganizaciones genéticas. En Mis demonios. Barcelona: Kairos.

Newell, A. y Simon, H. A. (1972). Human problem solving. Englewood Cliffs: Prentice Hall.

Novus, A. (s. f.). Biopoñitica y filosofia: del homo Sacer: la figura de la excepción soberana de Roma a nuestros dias. Recuperado en http://biopoliticayfilosofia.blogspot. com/2010/08/del-homo-sacer-la-figurade-la.html

Persky, J. (1995). Retrospectives: The Ethology of Economicus. The Journal of Economic Perspectives, 9(2), 221-231.

Ramírez González,P. (24 de diciembre de 2013). Décimas de noche ¿buena? Recuperado de http://carlosmramirezgonzalez.blogspot. com.co/2013/

Sánchez Meca, D. (2000). Martin Buber. Barcelona: Herder.

Sartori, G. (1998). Homo videns. La sociedad teledirigida. (A. Díaz, Trad.). Buenos Aires: Taurus-Alfaguara.

Scherer, K. y Giles, H. (Eds.). (1979). Social Makers in Spech. Cambridge: Cambridge University Press.
Schmidt, L. (1992). Hacia un nuevo Paradigma socio-religioso: "Homo Contemplans, Tradensque". Reflexiones generales sobre la oración y la meditación en el ser humano. Caracas: CEV-Cuadernos del INPAS.

Schmidt, L. (1994). La efectividad y la productividad ante la: pobreza, inteligencia y ética. Hacia el nuevo paradigma socio-político "homo productor". En Conferencia en la CLAT-UTAL. San Antonio de Los Altos, Venezuela.

Schmidt, L. (2011). Fe, ciencia y bioética. Revista Latinoamericana de Bioética, 11(21), 22-41.

Schmidt, L. (2012). El hombre como ser-trascendente: una perspectiva judeocristiana. Revista de Bioética Latinoamericana, 10, 53-99.

Teilhard de Chardin, P. (1999). Writings Selected (Trad. M. Blanco y R. Díez). Nueva York: Orbis.

Von Horrach, J. A. (2013). Disecciones Ensayos. Palma de Mayorca: Sloper.

Von Neumann, J. y Burks, A. W. (1966). The theory of self-reproducing automata. Urbana-Champaign: University of Illinois Press. 